Chloroform is the next panacea for man's aches and pains to which I direct attention. "To charm an ache with aix" is not a new discovery, strictly speaking, but only an old one utilised. Even as early as the twelfth century the following receipt is accredited to one Hugo da Lucca, an Italian physician:-“R. Opii et succi mori immaturi, hyoscyami, succi conidij, succi foliorum madragoræ, succi edereæ aboreæ, succi mori sylvestris, semi-lactucæ, seminis lapathij, quod habet poma dura, et rotunda, et cicutæ unam uncian." These medicines are directed to be boiled with sponge, and evaporated to dryness; then a portion of the dried sponge, steeped in hot water for an hour, is directed to be applied to the nostrils until stupor or insensibility is brought on. As soon as this soporific effect was produced, and prolonged so long as was deemed desirable, another sponge, dipped in hot vinegar, was applied to the nostrils to arouse the patient when the object for which he had been narcotised had been achieved.

Ether and chloroform, ${ }^{*}$ or rather their vapours, are the principal anæsthetics now in use in the practice of medicine; but the latter has almost superseded the former. And whatever opinions may be entertained as to the priority of the discovery of its value, there can be no doubt but we owe the extensive use of chloroform to the labours and example of the late Dr. Simpson, whose attention was turned to it in 1847. But probably the first suggestion of anæsthesia in surgical operations is due to Sir H. Davy, more than half a century ago. There is, then, more than poetry and satire in the expression "to charm an ache with air"; for, in the paroxysms of asthma, tetanus, \&c., it will act literally "as a charm," and cause the wondering patient to give utterance to the most lively expressions of gratitude for the relief one has been able to afford him.

In asthma, then, in tetanus, in the passing of gall-stones and urinary calculi, and in intestinal obstructions, internally by inhalations, and in neuralgia by its external and internal use, chloroform offers an invaluable agent for relieving pain; and should the time ever arrive when all danger to life shall be eliminated from its use, or should the scientific inquiries of $\mathrm{Dr}$. B. W. Richardson and other philosophers result in the discovery of an anæsthetic that shall be totally free from danger, they will give to the world the greatest boon it has ever received from science, and achieve and deserve an immortal name. And that this desirable object may speedily be accomplished I am not without good hope; for some recent experiments made by Dr. Richardson with methylic ether, and reported in THE LANCET, tend to show that we may yet discover ansæthetic agents which shall be free from all dangerous properties.
(To be concluded.)

\section{LIGATURE OF THE COMMON CAROTID ARTERY FOR ANEURISM; DEATH FROM CANCER OF THE RECTUM.}

By SAMPSON GAMGEE, F.R.S. EDIN., SURGEON TO THE QUEBN'S HOSPITAL, BIRMINGHAM.

THE subject of this report was sent to me by Mr. Sainthill Pearse, of Brierley Hill. I transcribe an abstract of the notes taken, on the patient's admission into the Queen's Hospital, by the Rev. T. Gregg, one of our students. ago, when at work in the pit, he felt a pain in the back of his neck and shoulders, without being able to account for it. The pain increasing, and a swelling being noticed in the left side of the neck, he consulted Mr. Sainthill Pearse, and left work on the 7th March. Appetite good, but feels pain in swallowing, which grows worse.

The tumour, visible over the left common carotid artery, extends from a little below the middle of the sterno-mastoid to the angle of the jaw, and from the left upper border of the thyroid cartilage to three inches backwards. Heartsounds normal; pulse 76 , equal on both sides.

On inspection, pulsation is distinctly visible. On palpa-

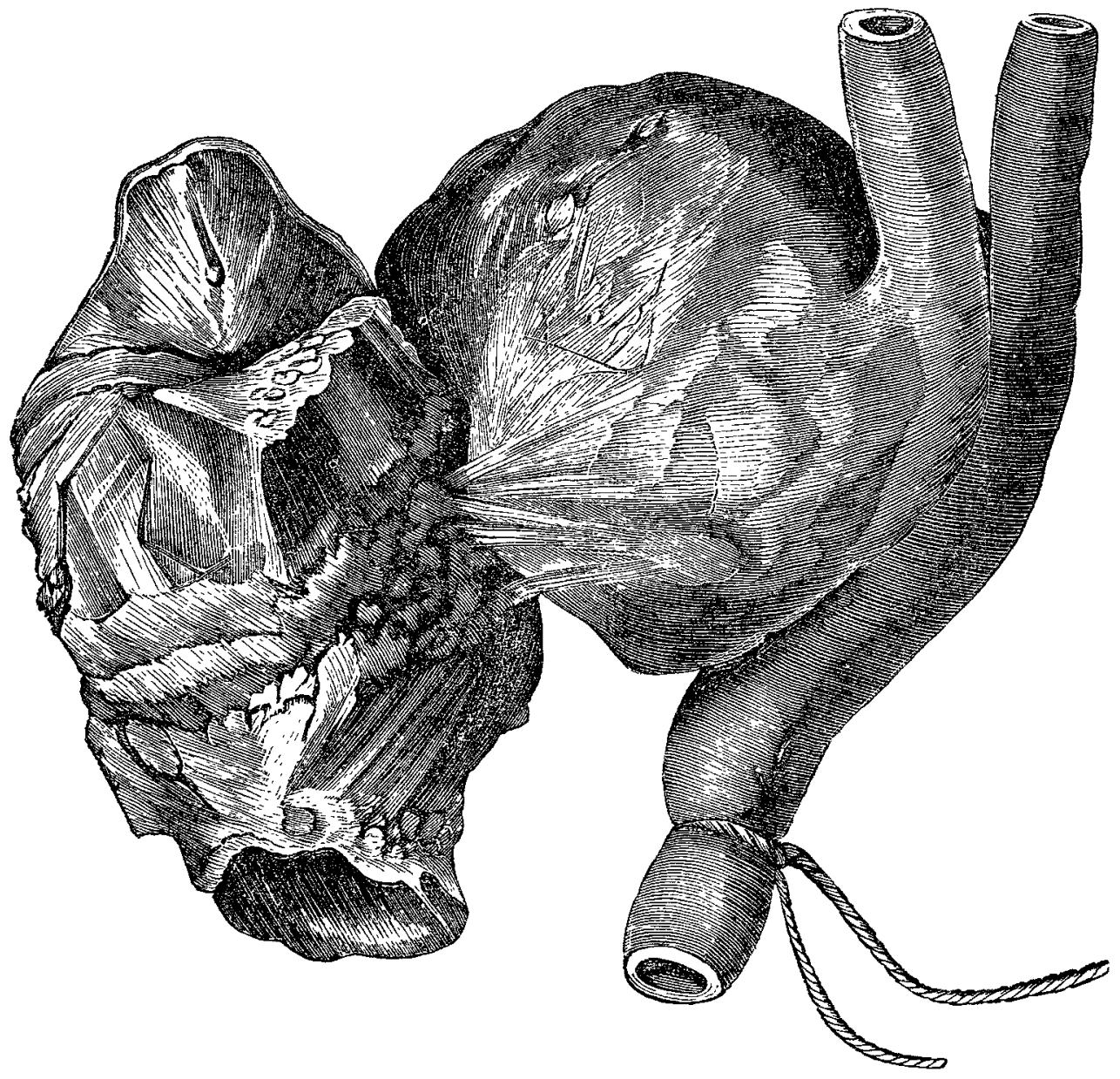

March 13th, 1871.-Uriah $\mathrm{M}_{-}$-_ , aged fifty-five, a miner. Aiways enjoyed good health, with the exception of an attack of rheumatic fever seven years since. About three weeks

* Bichloride of methylene has lately been extolled as an anæsthetic; but that it is superior to chloroform is yet to be proved. tion, a distinct thrill is felt in the tumour, especially over its posterior part nearest the carotid track. Expansion is easily felt by pressing the tumour laterally between the finger and thumb. On auscultation, two kinds of sound are clearly audible through the centre of the swelling: one 
being produced by the rush of air through the larynx, the other a loud rushing murmur due to the passage of blood; the former bruit perfectly synchronous with respiration, the latter with the motion of the heart. On pressing the carotid artery below the tumour, the pulsation is considerably diminished. There is neither swelling nor pain in any other part of the body.

The diagnosis of the aneurism was at once clear beyond the possibility of error. Equally evident was it that only one thing offered a chance of saving the man's life, and that was ligature of the common carotid. But, as $I$ observed more than once to the class at the bedside, the man's look was unsatisfactory - sallow and unhealthy. So much did I dislike his appearance, without being able to account for it, that I declined to operate one morning when the case was set down in the list of operations to be performed. The aneurism symptoms were not urgent at the time, and $I$ waited the effect of complete rest and good care, with which the man did certainly improve a little in general condition; but the growth of the aneurism and the rapidly increasing difficulty in swallowing and breathing forbad longer delay.

Operation.-I tied the left common carotid on April 15 th. I applied a waxed thread ligature on the vessel below the omo-hyoid. Only one little vessel was tied in the line of incision, which was closed with three silver sutures, and a light compress of dry lint held in position by a couple of strips of adhesive plaster.

After the operation the pulsation in the tumour ceased for some three or four hours, when it could be again felt very slightly. The tumour seemed scarcely more than half its previous size, and the patient expressed himself as comfortable and free from pain. He could hear much better, and was relieved from the incessant buzzing noise in the left ear and from the difficulty of swallowing and breathing.

April 16th.-The patient feels much better. No pain in wound or tumour; pulsation in it is stronger, and thrill plainly felt. No headache. Pupils act equally.

19th.-Pulsation and thrill diminished; tongue furred; pulse 95. Patient feels no pain anywhere, but is unable to micturate. Catheter passed morning and evening, and about four ounces of highly coloured urine drawn off each time.

20th.-10 A.Mr.: Pulsation still distinct; thrill barely perceptible, and that only in outer part of tumour, which is steadily diminishing in size; no headache; pupils act equally. Almost the whole of the wound has healed by the first intention; only very slight sanguineo-purulent discharge issues in the immediate neighbourhood of the ligature. Dry lint dressing renewed. The catheter again used for the relief of retention.-7 P.M. : Is quite comfortable in head and neck, but complains of sharp pain in the abdomen, especially on the left side; pain recurs in paroxysms. Bowels constipated. To have a warm-water enema, and two tablespoonfuls of castor oil by the mouth, which in the course of an hour produced a copious motion. Linseed-meal poultices to be applied to the abdomen, and a third of a grain of morphia to be administered by subcutaneous injection.

21st.-Abdominal pain very severe; knees drawn up in bed; the abdomen distended and tympanitic; pulse 130; extremities cold and clammy; face pinched, livid, and covered with perspiration. Is able to micturate, but with some difficulty. Symptoms of exhaustion increased, and death occurred at 7.35 P.Mr.

The register of temperatures throughont the case was taken by the resident surgical assistant, Mr. Wright Wilson, of whose notes I make an abstract:-

\begin{tabular}{|c|c|c|c|c|c|c|}
\hline \multirow[b]{2}{*}{ April 15: } & & \multicolumn{4}{|c|}{ Right Audit. Meatus. } & \multirow{2}{*}{$\begin{array}{l}\text { Left Meatus } \\
95 \cdot 4^{\circ}\end{array}$} \\
\hline & 12.20 noon & r. aft & op.) & $96 \cdot 4^{\circ}$ & $\ldots$ & \\
\hline פ, & 1.20 P.M. & $\ldots$ & $\ldots$ & $96.4^{\circ}$ & $\ldots$ & $96 \cdot 2^{\circ}$ \\
\hline , & 3.50 P.M. & $\ldots$ & $\ldots$ & $97 \cdot 4^{\circ}$ & $\ldots$ & $96.4^{\circ}$ \\
\hline , & 6.30 P.M. & $\ldots$ & $\ldots$ & $100^{\circ}$ & $\ldots$ & $98 \cdot 8^{\circ}$ \\
\hline & 8.30 P.M. & $\ldots$ & $\ldots$ & $100 \cdot 4^{\circ}$ & $\ldots$ & $98 \cdot 3^{\circ}$ \\
\hline April 16 & 8.30 Р.м. & $\ldots$ & $\ldots$ & $98 \cdot 2^{\circ}$ & $\ldots$ & $98 \cdot 4^{\circ}$ \\
\hline April 17 & 8.30 P.Mr. & $\ldots$ & $\ldots$ & $94 \cdot 6^{\circ}$ & $\ldots$ & $94.5^{\circ}$ \\
\hline April 18: & $\ldots$ & $\ldots$ & $\ldots$ & $92 \cdot 5^{\circ}$ & $\ldots$ & $93^{\circ}$ \\
\hline
\end{tabular}

At this date the temperature in the axilla had fallen to $98 \cdot 3^{\circ}$ from $101.8^{\circ}$, at which it stood the morning after the operation. At 8 P.M., April 19th, the thermometer marked $98 \cdot 8^{\circ}$, but it rose to $101 \cdot 2^{\circ}$ twenty-four hours afterwards, concurrently with complaint of sharp abdominal pain.

Autopsy, April 23rd, 10 A.Mr.-Very marked green dis- coloration on the front of the abdomen, espeeially on the right side, and on the corresponding half of the scrotum, the left half of which is of natural pink colour, the demarcation of the difference at the raphé being very distinct. Crackling perceptiole on pressure over the green discoloration; section through linea alba shows tissues discoloured and infiltrated with fetid sanies and gas. Intestines generally glued together by recent lymph, and peritoneum, parietal and visceral, deeply injected. The subperitoneal tissue in the lumbar and pelvic regions greatly distended with gas; the true pelvis filled with semi-purulent feculent matter. On carefully removing the bladder and rectum, the former is found to be healthy, but the lining membrane of the gut posteriorly, an inch and a half from the anus, presents a circular patch of ulceration nearly three-quarters of an inch in diameter; the ulcer extends through the coats of the bowel, communicating with the cavity of the pelvis, and is situated immediately over a solid mass, two inches in length by one inch in depth; this mass has been deposited in the areolar tissue beneath and behind the rectum; on cutting through it in the middle line it presents a fibro-cartilaginous appearance, of a bluish-white colour; it is very firm under the knife, and, on pressure, gives out a little opalescent juice. Our resident surgeon, Mr. Gilbert Smith, to whom I am much indebted for assistance throughout the case, has made a drawing of the microscopic appearances. Cells of

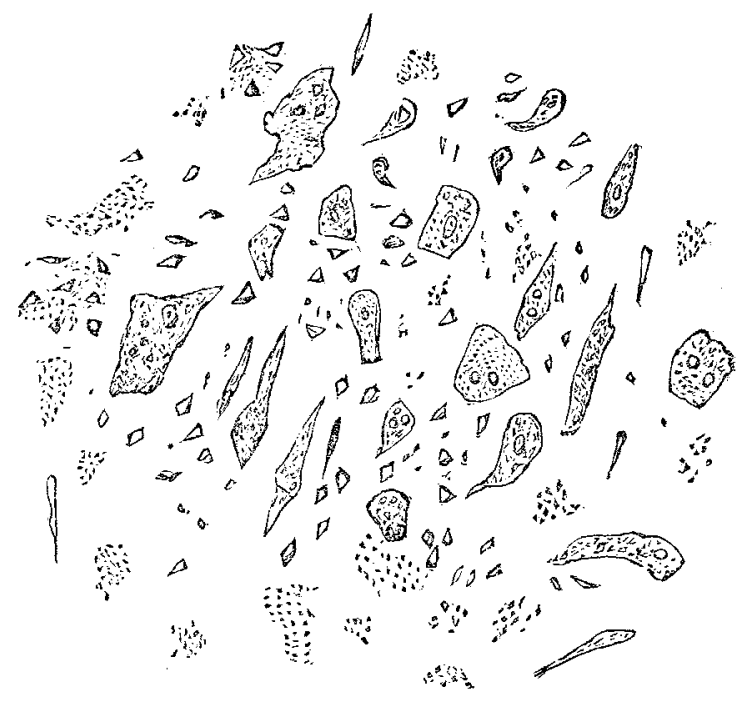

all shapes were visible in the field, round, square, caudate, and fusiform, many with large and compound nuclei; between the cells granular matter and free nuclei abounded. The cancerous nature of the deposit was beyond question. Patches of atheroma were visible in the aorta. No disease in other parts and organs.

Examination of the aneurism.-The wound firmly healed with the exception of one-eighth of an inch, where the ligature emerges. The thread is firmly embedded in the coats of the artery, surrounded by. plastic matter, at a point exactly one inch below the aneurism and three inches from the bifurcation of the common carotid. The dimensions of the aneurism are-laterally, two and a half inches; vertically, two inches. It presses against and is adherent to the larynx and pharynx, the former of which it overlaps a little on the left side. On opening the right external carotid from above, its cavity is quite free from clot, the lining membrane pink and smooth. The corresponding internal carotid at its margin is closed by a firmly adherent clot, which fills the cavity of the sac and extende down into the common carotid; in the sac the clot is reddish and rather soft, while in the common carotid it is white and much more solid and firmly adherent.

The coincidence of the two independent and formidable diseases is remarkable. Of the carotid aneurism nothing more need be said except that there is every reason to believe the ligature would have separated in due course without accident. Had there been reason to suspect cancer of the rectum, the artery must still have been tied to prolong life, which was in immediate danger from rupture of the bloody sac; but the fact is, we had no reason to suspect the disease of the bowel, and the man had distinctly denied pain in any other region of the body.

Birmingham, April, 1871. 